\title{
USLÛBA PESNÊ PÊXEMBER DI MEWLÛDA YEKEM A KURDÎ DE
}

\section{Türkan Tosun*}

\section{Kurte}

Di vê xebatê de behsa yekem mewlûda kurdî (kurmancî) Mewlûda Mele Huseynê Bateyî hatiye kirin. Mewlûda Bateyî di nav kurdan de gelek navdar e ku di medreseyan de piştî Qûr'anê zarok hînê mewlûda wî dibin û ev berhem ji bo mewlûdnameyên din jî bûye çavkaniyeke sereke. Ji bilî vê ev mewlûd di şîn û şahiyan de tê xwendin, ji ber vê di nav kurdan de berhemeke pir girîng e.

Di vê mewlûdê de Melayê Bateyî gelo çawa pesnê Pêxember daye, şêwazeke çawa bi kar anîye, kîjan rê û rêbaz û hunerên edebî bi kar anîye, bi zimanekî çawa nivîsandiye em li dû bersiva van pirsan ketin. Di gotarê de ewil pênaseya peyva mewlûdê hat kirin û dû re der barê kevneşopiya mewlûdê, jiyan û berhemên Bateyî de agahî hatin dayîn. Naveroka mewlûdê çi ye, Bateyî çawa behsa Pêxember kiriye, rêbazeke çawa bi kar anîye em li ser van mijaran sekinîn.

Peyvên Sereke: Mewlûda Bateyî, Mele Huseynê Bateyî, Mewlûda kurdî, Pesnê pêxember, Edebiyata klasîk a kurdî, Mewlûd

\section{THE STYLE OF PRAISING TO PROPHET IN THE FIRST KURDISH MAWLID}

\begin{abstract}
This paper reviews the earliest Kurmanji-Kurdish mawlid written by Mullah Huseynê Bateyi. The Mawlid of Bateyi is very popular among the Kurds as children used to read it in madrasahs after learning how to read the Qur'an. Having served as a source for subsequent mawlids, Bateyi's Mawlid is recited in special occasions such as celebrations and mournings.

This study first provides a definition of the word mawlid. Then, it goes into a brief presentation of the life and work of Bateyi. Finally, this paper analyzes Bateyi's Mawlid with a particular attention to the following questions: how does Melayê Bateyi praise the Prophet in his Mawlid? What kind of a literary style does he use? What methods and literary arts does he employ? What kind of a linguistic style does he use in penning his work?
\end{abstract}

Article Types / Makale Türü: Research Article / Araştırma Makalesi

Received / Makale Geliş Tarihi:22.10.2019, Accepted / Kabul Tarihi: 27.12.2019

Doi: $10.26791 /$ sarkiat. 636128

* Türkan Tosun, Xwendekara Doktorayê, Zanîngeha Bîngolê, Beşa Ziman û Edebiyata Kurdî tosunturkan@gmail.com

ORCID ID: https://orcid.org/0000-0002-3815-262X 
Keywords: Mullah Huseyni Bateyi, Bateyi's mawlid, Kurdish mawlid, Praising the Prophet, Classical Kurdish Literature, Mawlid

\section{DESTPÊK}

Ayeteke Qur'ana Pîroz dibêje "Me tu tenê ji bo hemû mirovan wek mizgînîdêr û hişyarker şand. Lê piraniya mirovan nizanin"'. Wek di vê ayetê û gelek ayetên din de jî tê gotin Hz. Mihemed qasidê Xwedê ye û ji bo mirovan hatiye şandin ku ji wan re bibe rêber. Mirovên ku bûne misilman û rêberiya wî qebûl kirine him bi ayetan, him jî bi sunet û hedîsan ve Hz. Mihemed şopandine û bi hezkirin pesnê wî dane. Hin alim û nivîskarên misilman xwestine bi nivîsê pesnê xwe bidin nîşan, ji ber vê jî dest avêtine qelemê û berhemên pesnê Hz. Pêxember didin nivîsandine ku ji wan re dibêjin mewlûd. Alim û nivîskarên kurd jî helbet di vê qadê de hunera xwe nîşan dane. Li gor agahiyên berdest di nav kurdan da kesê ku ewil ev cure berhem nivîsandiye Mela Huseynê Bateyî ye. Paşê hin kesên din çav dane wî û mewlûd nivîsandine ku me navê wan kesan û mewlûdên wan li jêrê rêz kir.

Gelo Bateyî mewlûdek çawa nivîsandiye, pesnê pêxember çawa daye, me hewl da ku em di vê xebatê de mewlûda wî ya navdar binirxînin. Li ser jiyan, berhem û mewlûda wî helbet gelek tişt hatine gotin û nivîsandin, lê me xwest li ser vê mijarê em jî çend tiştan zêde bikin.

\section{Têgeha Mewlûdê, Jîyan û Berhemên Mela Huseynê Bateyî}

\section{2. Têgeha Mewlûdê}

Di edebiyata klasîk a kurdî de mewlûd cureyek girîng e ku bi şiklê menzûm an jî pexşan ji dayikbûnê bigre heta mirinê behsa jiyana Hz. Mihemed (s.x.l) dike. Mewlûd peyveke erebî ye û koka wî ji tîpên "v, l, d" (ولد) tê. ${ }^{2}$ Ev peyva ku ji peyva "weladet"ê hatiye çêkirin tê çend meneyan ku yek ji wan "jidayikbûn", yek "cihê jidayikbûnê" û ya din jî "dîroka jidayikbûnê" ye. Di mewlûdê de gelemperî behsa jidayikbûna pêxember (welâdet), pêxemberiya wî (risalet), jiyan û exlaqê wî, şerên ku kirine, mîrac, mucîzeyên wî, ji Mekkeyê çûyîna wî ya ber bi Medîneyê (hicret) û wefata wî (rihlet) tê kirin. ${ }^{3}$ Di nav gelek civakên misilman de mewlûd nivîsandin, xwendin û wek seremonî pîrozkirin ji berê va heye û wek kevneşopî dewam dike.

Li gor agahiyên berdest berhemên wek mewlûd tên hesibandin û pîrozkirina mewlûdê ewil di nav ereban de dest pê kiriye, paşê di nav civakên din ên misilman de belav bûye. Di alema îslamê da berhema ewil a wek mewlûd tê zanîn berhema Ebu'l-Ferec el-Cevzî ya bi nave "Mevlîdû'n-Nebî" ye. Piştî wê berhemên Ebu'l-Qasim es-Sebtî, Îbn Dîhye, Zemlakanî jî di nav mewlûdên ewil da dikarin bên nîşandan. ${ }^{4}$

Kesên ku mewlûd nivîsandine yên erebî ji xwe re kirine jêderk û li gor van bi zimanê xwe yê dayikê mewlûd amade kirine. Di nav demê de mewlûd ji bilî nivîsandin û

\footnotetext{
${ }^{1}$ Sebe $34 / 28$.

2 Rabia Doğru, "Kara Vâîz ve Mevlid'i”, Ondokuz Mayıs Üniversitesi Illahiyat Fakültesi Dergisi 0/39 (2015): 222.

${ }^{3}$ Ramazan Ekinci, "Behiştî Mahlaslı Şairlere Ait Mevlitler, Behiştî Ahmed Sinan'ın Mevlid-i Şerîfi”, Sufî Araştırmaları Dergisi 5/10 (Yaz 2014): 17.

4 Süleyman Eroğlu, "Edebî Bir Tür Olarak Mevlitler-Şekil Özelliklerine Göre Bazı Değerlendirmeler”, U. U. Fen Edebiyat Fakültesi Dergisi 11/18 (2010): 126-127.
} 
xwendinê, di salvegera jidayikbûna Hz. Pêxember de wek pîrozbahî, merasim û rîtûel jî hatiye pîrozkirin. Helbet çawa ku di nav gel û civakên din de mewlûd hatine nivîsandin, di nav kurdan de jî ev berhem derketine holê. Qasî ku tê zanîn yekem mewlûda kurdî ji hêla Melayê Huseynê Bateyî ve di sedsala 17emîn de hatiye nivîsandin (lewra Bateyî di navbera sedsala 17-18emîn de jîyaye) $)^{5}$. Piştî Bateyî kesên din jî berhem dane û gelek mewlûdên din di edebiyata kurdî de cihê xwe girtine. Mewlûda Bateyî ya ku ji 600 beytan (ji ber destxetên cuda hejmara beytan diguhere) pêk tế ${ }^{6}$ ji bo mewlûdên din bûye jêderk û tesîra wê li ser mewlûdên din çêbûye ${ }^{7}$. Her çiqas piştî vê berhemê gelek mewlûd hatibin nivîsandin jî, qasî mewlûda Bateyî ew navdar nebûne û derneketine pêş. Piştî Bateyî hin mewlûdên kurdî yên ku hatine nivîsandin jê hinek ev in;

\section{Mewlûdên ku bi kurmancî hatine nivîsandin}

Mewlûda Bateyî: Mela Huseynê Bateyî

Mewlîdî Nebî: Şêx Muhemmed Emînê Heyderî

Mewlûda Şerîf: M. Zahit Kardeşlik

Fêkiyê Narencî Mewlûda Kurmancî: Ehmed Nas

Mewlûda Şerîf: Mela Muhemmed Elî Fudeylî

Mewlûda Nebî: Mela Şewqî Xak

Mewlûda Pêxember: Mela Silêman Kurşun

Mewlûda Kurdî Bi Şêwaza Hedbî: M. Burhan el-Hedbî

Mewlûda Fexrê 'Alemê Muhemmed: Seyîd Mela Ebdurrehman Kurê Mela Hemze

Ava Heyat: Mela Elî bîn es-Seyid 'Evdirrehman

\footnotetext{
${ }^{5}$ M. Xalid Sadinî, Mela Huseynê Bateyî Jiyan, Berhem û Helbestên Wî, Çapa Yekem (Stenbol: Weşanên Nûbihar, 2010), 4.

${ }^{6}$ M. Xalid Sadinî, "Mela Huseyînê Bateyî, Jîyan û Berhemên Wî”, Uluslararası Beytuşşebap Ve Molla Hüseyin Bateŷ̂ Sempozyumu (Şırnak, 20-21 Eylül 2014), ed. İbrahim Baz (İstanbul: Şırnak Üniversitesi Yayınları, 2015), 99.

${ }^{7}$ Kesên ku bixwazin tesîra Bateyî li ser mewlûdên din bibînin dikarin destpêk, neqerat, ziman, şêwaz û naveroka mewlûdên din binêrin. Çend hevokên ji du mewlûdan (mewlûdên Süleyman Kurşun û Mela Eliyê Baqustanî) li vir dikarin ji bo mînakê bên nîşandan. Bateyî dibêje;

"Merheba ey sirrê furqan merheba

Merheba dermanê derdan merheba"

Mele Süleyman Kurşûn jî wek Bateyî peyva merhebayê bi kar aniye;

"Merhaba ey "ebdê Salih xweş were

Merhaba derdê dila ra dawer e"

Melayê Bateyî di neqerata (dîsgotin) mewlûda xwe de dibêje;

Ger divêtin hûn ji narî binnecat

Bi eşq û şewqek hûn bibêjin es-selat

Mela Eliyê Baqustanî jî di mewlûda xwe de wiha dibêje;

"Ger dixwazin hûn xelabin ji 'ezab

Din selata ser Muhemmed bê hisab"

Ji bo berawirdiya Mewlûda Melayê Bateyî û Süleyman Kurşun gotara Hasan Karacan û Nurettin Aykut a bi navê “Mele Hüseynê Bateyî'nin Mewlid-i Nebî Adlı Eseri İle Mele Süleyman Kurşun'un Mewlida Pêxember Adlı Eserinin Karşılaştırılması" dikare bê xwendin. Ji bo mînaka din a me nîşan da jî pirtûka "Mewlûda Mela Eliyê Baqustanî- Metn û Lêkolîn" dikare bê xwendin. Ev makale û pirtûk di çavkaniyê da hatin nîşandan.
} 
Mewlûda Şerîf Ji Ewwel Heta Axir Rêberê Xelasê: M. Mustefa yê Mela 'Aliyê Ezdarî

Kitêba Dura Birîncî Mewlûda Kurmancî: Mela Muhemmed Siraceddînê kurê Ebdilhekîmê Xelîlî

Mewlûda Kurdî Bi Zimanê Gundî: Seyîd Bedreddîn Ibn Mela Salih El-Hesenê Şefi'’î El-Kefsurî

Nezma Şerîn Der Mewlîd û Sîreta Resulê Emîn: Mela Muhemmed kurê Mele Ehmedê Xursî

Mewlûdên ku bi kirdkî (zazakî-dimilkî) hatine nivîsandin

Mewlidê Nebiyê Qûreyşî: Ehmedê Xasê

Biyîşê Pêxemberî: Osman Efendiyo Babij

Mewlîdî Pêyxemberî: Mela Mehemed Elî Hûnî

Mewlîdî Nebî: Mela Kamilê Puexî

Mewlîdî Zazakî: Mela Mehemedê Muradan ${ }^{8}$

Mewlûdên bi soranî-hewramî hatine nivîsandin

Mewlûdname: Şêx Huseyn Qazî

Mewlûda Pîremêrd: Pîremêrd

Mewlûd: Mehemed Emîn Beledî Şinewî

Mewlûd: Mamosta Mehemed Qadî Xidrî Eşnewîye

Mewlûd: Mamosta mela 'Ebdulkerîm Muderrîs

Mewlûd: Mamosta Mela 'Umer Nûrbextî Neqde

Mewlûd: Mamosta Celî Zade

Mewlûd: Kak Ehmed Muftîzade

Mewlûda Mûfessel: Mamosta Mela Hadî Efxemzade

Mewlûda Muxteser: Mamosta Mela Hadî Efxemzade

Mewlûdname ê Kûkerdnewe: Mamosta Mela Muhemedê Şelmaşî

Mewlûdnamew Pêxemberî: Şêx Nesîm Texteyî

Mewlûd: Mamosta Rehman Huseyînzade

Mewlûdnamey Kurdî: Reşad Mehemmed Miftî

Mewlûdname ê New Eser Ya Tarîxê Pexember: Şêx Mûhemmed Xal

Mewlûda Seyyid Muhemmed Şemsê Qureyşî: Seyyid Muhemmed Behaeddîn Şems Qureyşî

Mewlûdên bi goranî hatine nivîsandin

\footnotetext{
8 Zîver Îlhan, Mewlûda Mela Huseynê Bateŷ̀ Metnê Rexneŷ̂ $\hat{u}$ Lêkolîn, Çapa Yekem (Stenbol: Weşanxaneya Avaesta, 2016), 16-17.
} 


\section{Mewlûdnamew Pêxemberî: Seyyid 'Ebdullahê Weblberî̀}

Wek xebatên din ên kurdolojiyê li ser mewlûdan jî her ku diçe lêkolînên xurt tên kirin û agahiyên nû li ser van xebatan zêde dibin. Ji bilî vê lîsteya ku me da mewlûdên din jî hene. Zahîr Ertekîn û Nurettîn Ertekîn di gotarekê de behsa kurtedîroka mewlûdan kirine, balê kişandine li ser hejmara mewlûdan û li gor kronolojiyê tabloyeke ku navê 60 mewlûdên kurdî (zazakî, kurmancî, soranî-hewramî û goranî) tê de hene amade kirine. $^{10}$

\section{Jîyan û Berhemên Mela Huseynê Bateyî}

\section{1. Kurtejiyana wî}

Mela Huseynê Bateyî di edebiyata klasîk de navekî pir girîng e. Di dewra ku jiya ye de wek helbestvan û seydayekî kurd kesekî navdar bûye, lê piştî miriye nav û dengê wî zêdetir belav bûye. Der barê nav û jiyana wî de hin niqaş hene ku tê gotin navê wî Ehmed, Mihemed an Huseynê Ertûşî ye, lê M. Xalid Sadinî bi çend xal û delîlan ve nîşan dide ku navê wî Huseyn e. ${ }^{11}$ Ji bo serdema jiya ye jî nakokî zêde ne, lê Sadinî piştî gelek çavkanî, şîrove û nirxandinan der barê vê mijarê de jî dibêje ew di sala 1680an de hatiye dinyayê û 1760 an de wefat kiriye. ${ }^{12}$

Mela Huseynê Bateyî li gundê Bateyê ya ku dikeve rojhilatê Beytuşşebabê (Elke) di nav eşîra Ertûşiyan de hatiye dinyayê, bavê wî Mele Mistefa ye. ${ }^{13}$ Heta 15 saliya xwe li cem birayê xwe Ehmed ê ku li gundê Pîrûsiyan mele bû xwendiye û paşê li Medreseya Mîr Zeynel Begê Hekarî perwerde dîtiye. Ji bilî kurdî erebî, farisî û tirkî jî zanibûye. ${ }^{14}$ Mela Bateyî piştî xendina wî xilas bûye li gundê Pîrosa nêzîkî Bateyê dest bi melatiyê dike, li wir bi Hemayil Xanimê re dizewice û dibe xwedî zarokan. ${ }^{15}$ Du qîz û kurekî wî çêbûne ku navê zarokên wî Tahir, Zulfê û Asmîn e. ${ }^{16}$

\section{2. Berhemên Wî}

Berhemên Mela Huseynê Bateyî qasî ku hatine bi dest xistin ev in; Mewlîda Nebî, berhemeke pexşan a bi navê Hemaîl (bi erebî hatiye nivîsandin) û bi qasî dîwançeyekê helbestên cur be cur (munacaat, ne'et û evînî). Li gor Qanatê Kurdo manzûmeya evînî Zembîlfiroş jî berhema wî ye, ${ }^{17}$ lê li ser vê berhemê fikreke hevpar tune. Lewra Xalid Sadinî behsa vê berhema Bateyî nake. ${ }^{18}$

\footnotetext{
9 M. Zahir Ertekin-Nurettin Ertekin, "Kurtedîroka Mewlûdnameyên Kurdî”, Şarkiyat ICSS'17 Uluslararasi Sosyal Bilimler Kongresi/International Congress of Social Science, (Diyarbakır, 14-17 Eylül 2017) ed. Mehmet Bilen (Diyarbakır: Şarkiyat Vakfı, 2017), 152-153-154.

${ }^{10}$ Ertekin, "Kurtedîroka Mewlûdnameyên Kurdî”, 152-153-154.

${ }^{11}$ Sadinî, Mela Huseynê Bateyî Jiyan, Berhem î Helbestên Wî, 19-20.

12 Sadinî, Mela Huseynê Bateyî Jiyan, Berhem û Helbestên Wî, 30.

13 Abdurrahman Adak, "Destnivîsên Mewlûda Melayê Bateyî Di Arşîva A. Jaba De: Nasandin û Analîz", The Journal Of Mesopotamian Studies 2/2, (Havîn: 2017): 4.

${ }^{14}$ Sadinî, Mela Huseynê Bateyî Jiyan, Berhem û Helbestên Wî, 30.

15 Abdurrahman Adak, Destpêka Edebiyata Kurdî Ya Klasîk, Çapa 3yemîn (Stenbol: Weşanên Nûbihar, 2015), 275.

${ }^{16}$ Sadinî, Mela Huseynê Bateyî Jiyan, Berhem û Helbestên Wî̀, 31.

${ }^{17}$ Qanatê Kurdo, Tarîxa Edebiyata Kurdî, Çapa Yekem (Diyarbekir: Weşanên Lîs, 2010), 84-85.

${ }^{18}$ Xalid Sadinî di pirtûka xwe da behsa vê berhemê nake. Ez ji bo ku emîn bibim, min rasterast ji şexsê wî pirsî, lê got ji ber ku gotinên Qanatê Kurdo bêdelîl in wî behsa vê mijarê nekiriye.
} 


\section{Mewlûda Nebî û Naveroka Wê}

Mewlûda Huseynê Bateyî di nav kurdan de mewlûdeke bi nav û deng e, di medreseyên kurdan, şîn û şahiyên wan de tê xwendin. Ev mewlûd di nav gelê kurd de bûye berhemeke girîng û bi saya wê hezkirina Hz. Pexember zêde bûye. Der barê beş, rûpel û beytên mewlûdê de agahiyên cuda li holê hene, sedema vê jî nusxayên cuda ne. Ya ku me li ser xebat kir nusxaya M. Xalid Sadinî çap kiriye ye. Ev mewlûd ji 18 beşan û 600 beytan pêk tê. Melayê Betayê di vê berhemê de bi zimanekî zelal û xurt ji afirandina Adem Pêxember bigre heta jidayikbûna Hz. Mihemed behsa wî kiriye, bi hezkirin û heyranî pesnê wî daye.

Li gor nûsxeya li ber destê me Melayê Bateyê mewlûda xwe bi tevî paşgotinê wek 18 beş amade kiriye. Hin beş kin, hinek normal û hinek jî dirêj in. Beşên mewlûdê gelemperi di navbera 11 û 40 beytan de hatine nivîsandin, lê jê hinek dirêj in wek beşa "Hatina Helîma se'dî bo Mekkehê û birina Pêxemberî" (58 beyt) û "Pêxember li nav ûcaxa se'diyan" (68 beyt). Li ser beşan nav hatine nivisandin û di dawiya wan de neqerat (dîsgotin) hene. Mewlûd ji van beşan pêk tê;

1- Hemd bo Xwedê, 2- Selat ji bo Pêxember, 3- Xêra xwendina mewlidê, 4- Afirandina ronahiya Pêxember, 5- Afirandina Adem Pêxember, 6- Neseba Pêxember, 7- Bûna 'Ebdullah û geheştina ronahiya bo wî, 8- Bergeryana Cihûyan da 'Ebdullah bikujin, 9Zewaca 'Ebdullahî û Amîneyê, 10- Giraniya Amîneyê bi Pêxember, 11- Bûna Pêxember, 12- Ew tiştên li şeva bûnê çêbûne, 13- Ew nîşanên 'Ebdulmutttelib di wê rojê de dîtin, 14- Hatina Helîma se'dî bo Mekkehê û birina Pêxemberî, 15- Zivirîna karwanê se'diyan ji Mekkehê, 16- Pêxember li nav ûcaxa se'diyan, 17- Zivirîna Pêxemberî li Mekkehê, 18- Paşgotin ${ }^{19}$

Mewlûda Bateyî wek ku hat gotin bi varyasyonên cuda hatine çapkirin, ji ber vê jî di hinekan de navê hin beşan an diguherin, an jî tune ne. Lê gelemperî wek beşên ku me rêzkirin derdikevin pêşberî me. Her beş di nav xwe de ji gelek beytan pêk tê. Ev beyt di dawiya hemû beşan de wek neqerat (dîsgotin) hatiye nivîsandin;

Ger divêtin hûn ji narî binnecat

Bi eşq $\hat{u}$ şewqek hûn bibêjin es-selat

Ji bilî beşa "Bûna Pêxember" ev di dawiya beşan de hatiye nivîsandin, lê bi tenê di vê beşê de him navîna beşê̂ û him jî di dawiya beşê de hatiye dubarekirin. Ji ber vê bi tevahî di mewlûdê de ev neqerat 19 caran hatiye dubarekirin. Naveroka beşan wiha ye;

1- Hemd bo Xwedê: Ev beşa ewil ya bi hemd û şikra Xwedê ve dest pê dike ji 11 beytan pêk tê. Di vê beşê de behsa mezinbûna Xwedê tê kirin û hin sifatên wî tên rêzkirin.

2- Selat ji bo Pêxember: Ji 13 beytan pêk tê û di vê beşê da selat û selam ji bo Hz. Mihemed (s.x.1.) tê kirin.

3- Xêra xwendina mewlidê: Di vê beşa sêyemîn de behsa xêr û fezîletên xwendina mewlûdê hatiye kirin. Ev beş ji 21 beytan pêk tê. Tê gotin di mala ku mewlûd tê de bê xwendin ji qeza û belayan dûr dibe, pereyê ku ji bo mewlûdê tê xerckirin jî ji bo însanan bibereket û xêr e.

\footnotetext{
${ }^{19}$ Navê beşan di pirtûka M. Xalid Sadinî de çawa hatibe nivîsandin, me jî li gor wê nivîsand.
} 
4- Afirandina ronahiya Pêxember: Ev beşa ku ji 33 beytan pêk tê behsa afirandina ronahiya Hz. Mihemed (s.a.v.), afirandina kaînatê dike. Dîsa di vê beşê de behsa ummeta Hz. Mihemed tê kirin û tê gotin ew ji ummetên din zêde ne û bi qîmettir in.

5- Afirandina Adem Pêxember: Wek ku ji navê wê jî tê fêmkirin di vê beşê de behsa xuliqandina Hz. Adem, li ber wî secdekirina milyaketan tê kirin. Ji 39 beytan pêk tê.

6- Neseba Pêxember: Di vê beşê de 11 beyt hene. Tê de behsa navê şecereya Hz. Mihemed tê kirin û pesnê esl û neslê wî tê dayîn.

7- Bûna 'Ebdullah û geheştina ronahiya bo wî: Ev beş ji 35 beytan pêk tê, di vê beşê de behsa jidayîkbûna Ebdullahê bavê Hz. Pêxember tê kirin.

8- Bergeryana cihûyan da 'Ebdullah bikujin: Ji 20 beytan pêk tê. Melayê Bateyî di vê beşê de behsa cihûyan dek û dolabên wan ên ji bo kuştina Ebdullahê bavê Hz. Pêxember dike.

9- Zewaca 'Ebdullahî û Amîneyê: Bateyî di vê beşê de 50 beyt nivîsandine û behsa zewac û dewata Ebdullahê bavê Hz. Pêxember û diya wî Amîneyê kiriye.

10- Giraniya Amîneyê bi Pêxember: Ev beş ji 25 beytan pêk tê. Giraniya Amîneyê ya bi Hz. Pêxember her meh mizgîniya ku ji wê re tê dayîn ku ewê pêxemberekî bîne dinyayê di vê beşê de mijar in.

11- Bûna Pêxember: Beşa ku behsa jidayîkbûna Hz. Mihemed dike ev beș e û ji 49 beytan pêk tê. Dema ew tê dinyayê hin bûyer diqewimin ku ew jî wek mijar di vê beşê de cih digrin.

12- Ew tiştên li şeva bûnê çêbûne: Roja ku Hz. Pêxember tê dinyayê hin mucîze çêdibin ku Melayê Bateyî di vê beşê de bi 18 beytan ve behsa wan mucîzeyan kiriye.

13- Ew nîşanên 'Ebdulmuttelib di wê rojê de dîtin: Ev beş ji 21 beytan pêk tê. axaftina Ebdulmuttelibê kalikê Hz. Mihemed a bi dayika wê Amîneyê ra, bûyerên ku dema ew tê dinyayê diqewimin di vê beşê de tên behskirin.

14- Hatina Helîma Se'dî bo Mekkehê û birina Pêxemberî: 58 beytên vê beşê behsa Helîmeya Se'dî ya ku şîr daye Hz. Pêxember dike. Ew çawa tê Mekkeyê, çawa Hz. Mihemed dibe ku xwedî bike û bimijîne li vir tê behskirin.

15- Zivirîna karwanê se'diyan ji Mekkehê: Ji 25 beytan pêk tê ev beş û behsa vegera karwana Sa'diyan a Mekkeyê dike.

16- Pêxember li nav ûcaxa se'diyan: Dema Helîmeya Sa'diyan Hz. Pêxember dibe nav êl û eşîra xwe bereketa wî li ser wê eşî û axê çêdibe. Ev beş ji 68 beytan pêk tê, Melayê Bateyî li vir behsa bereketa Pêxember ya ku derketiye holê dike. Melayê Bateyî behsa vê bereketa çêbûye dike. Dibêje bi hatina wî ve heywanan zêde şîr dane, erd bi bereket bûye û h.w.d.

17- Zivirîna Pêxemberî li Mekkehê: Ev beş ji 49 beytan pêk tê. Li vir tê gotin Helîme Hz. Mihemed dibe Mekkeyê û paşê behsa vegera wî ya ji Mekkeyê tê kirin. 
18- Paşgotin: Mewlûd li vir dawî dibe û ev beşa encamê ye. Ji 25 beytan pêk tê û tê de behsa sifatên Hz. Mihemed tên kirin. ${ }^{20}$

\subsection{Wezna Mewlûdê}

Mewlûda Bateyî bi awayekî menzûm bi wezna arûzê, qaliba fâ'ilâtûn/fâ'ilâtûn/fâ'ilûn hatiye nivîsandin. Çavkaniya wezna arûzê edebiyata ereban e ku di risteyan de li gor dirêjahî û kinbûna kîteyan tê tespîtkirin. Divê her riste ji hêla deng va wek hevdu bin. Kîteya bi tîpek dengdêr va qediyaye "kîteya vekirî" ya ku bi tîpeke dengdar va qediyaye jî "kîteya girtî" ye. Kîteyên vekirî bi sembola xalê (.) û yên girtî jî bi xêzeke kin (-) tên nîşandan. Ev cure wezn di berhemên klasîk de tê bikaranîn û mewlûd jî bi vê weznê ve hatiye nivîsandin. Mînak;

Ew Xwedayê malikê mulkê 'ezîm

Daye me mîrasa Qur'ana Kerîm ${ }^{21}$

\subsection{Zimanê Mewlûdê}

Mela Huseynê Bateyî yekem kes e ku bi zimanê kurdî mewlûdek nivîsandiye. Ev taybetmendî bûye sedem ku di nav kurdan da qîmeta mewlûdê zêde bibe. Her çiqas mewlûd kurdî (kurmancî) bê nivîsandin jî, hin caran di bin tesîra zimanê erebî û farisî de maye. Mirov gelemperî binirxîne di mewlûdê de serdestiya kurdî heye. Peyv û gotinên kurdî yên resen bi awayekî rewan di berhemê de hatine bikaranîn. Ji bo ku zimanê kurdî di mewlûdê de çawa hatiye bikaranîn û zelalbûna wê bê dîtin mirov dikare gelek hevokan mînak nîşan bide, lê me ev beyt dan;

Paşî hingî xaliqê her sûretê

Çêkirî Adem bi destê qûdretê

Pif kirî ruha xwe ew bû nazenîn

Lew melek hatin ji bo wî sacidin 22

Wek ku tê dîtin gelemperî peyv kurdî ne, zimanekî zelal di mewlûdê da heye. Lê wek ku li jorê jî hat gotin tesîra erebî li ser mewlûdê zêde ye û ji bo vê mijarê ev beyt dikare bibe mînak;

Ewwela Lefza wî min maye li bîr

Gotî wî: Allahû ekber min kebîr ${ }^{23}$

Di vê beyta Melayê Bateyî de peyvên erebî “ewwel, lefz, Allah, ekber, kebîr” xwe didin nîşandan.

Ji bilî erebî peyvên farisî jî di mewlûda Melayê Huseynê Bateyî de hene ku wek;

Xweş divê babê ezîzê maderî

\footnotetext{
20 Hasan Karacan-Nurettin Aykut, "Mele Hüseynê Bateyî’nin Mewlid-i Nebî Adlı Eseri İle Mele Süleyman Kurşun'un Mewlida Pêxember Adlı Eserinin Karşılaştırılması”, Bingöl Üniversitesi Yaşayan Diller Enstitüsü Dergisi 1/2, (Kasım: 2015): 124.

${ }^{21}$ Sadinî, Mela Huseynê Bateyî Jiyan, Berhem û Helbestên Wî, 175.

${ }^{22}$ Sadinî, Mela Huseynê Bateŷ̀ Jiyan, Berhem û Helbestên Wî, 184.

${ }^{23}$ Sadinî, Mela Huseynê Bateyî Jiyan, Berhem û Helbestên Wî, 221.
} 
Rohniya malê û zîba esmerîn ${ }^{24}$

Di ve beytê de jî peyvên "mader" û "zîba" peyvên farîsî ne ku Bateyî ew bi kar anîne.

\subsection{Uslûba Mewlûdê}

Berhemeke edebî dema tê xwendin, behsa wê tê kirin an jî li ser lêkolîn tên kirin hin taybetmendî û pirs derdikevin pêş. Gelo nivîskarê wê kî ye, berhem kingê hatiye nivîsandin, ziman û şêwaza wê çawa ye, bi kîjan metodan ve hatiye nivîsandin? Dema em bibêjin uslûb, şêwaz divê çi bê fêmkirin niha em hinekî li ser vê rawestin.

Uslûb peyveke erebî ye û meneya wê vegotin, îfade, tarz û rêbaza kirinê ye. ${ }^{25} \mathrm{Ji}$ hêla edebî ve jî taybetmendiya vegotin û nivîsandina kesekî ye. Bi hevokan, bi şiklê nivîsandinê, bi peyv û gotinên hatine bikaranîn, bi metoda nivîsandinê, metafor, sembol, maxlas û tiştên bi vî rengî ve şewaza nivîskar nîşan dide. Wek neynikekî xususiyetên wî yên nivîsandinê, şopên kesayetiya wî, binhişê wî, alema wî ya hundirîn, ziman, hest, hiş û ramanên wî dide der. Yên ku berhemekê dixwînin ji ber van xusiyetan texmîn dikin nivîskarê wê berhemê kî ye, ew berhem kingê hatiye nivîsandin, nivîskar girêdayî kîjan ekolê ye û h.w.d.

Him di edebiyata klasîk û him jî ya modern de her şair û nivîskar xwedî uslûbekê ye, li gor vê usluba xwe dinîvîse, ber û berhemên xwe pêşkeşî xwîneran dike. Emê niha hinekî behsa uslûb ango şêwaza Melayê Bateyî bikin ka wî mewlûd bi şêwazeke çawa nivîsandiye. Melayê Bateyî helbestvanekî edebiyata klasîk e. Ji ber ku serdema jiyaye zimanên erebî û farisî serdest bûn, wî jî ev ziman di berhemên xwe de zêde bi kar anîne. Lê Bateyî gaveke mezin avêtiye ku ev gava wî cudahiyê dike navbera wî û helbestvanên wê demê. Ev cudahî jî ew e ku wî bi zimanê xwe, yanê bi kurdî mewlûdek nivîsandiye, ev xaleke pir girîng e. Di mewlûdê de Bateyî ewil ji bo Xwedê hemd û paşê selata ji bo Hz. Mihemed dest bi mewlûda xwe dike;

"Hemdê bêhed bo Xudayê 'alemîn

Ew Xudayê daye me dînê mubîn

Em kirine Ummeta Xeyru'l-Beşer

Tabi'ê wî muqtedayê nam(i)wer" 26

Di dawiyê de ji bo hemû misilmanan diayan ji Xwedê dike. Herî dawîn dixwaze kesên ku mewlûdê dixwînin ji bo wî Fatihayekê bixwînin. Çend rêzikên pesnê pêxember didin heke bên nîşandan mirov dikare van hevokan mînak bide;

Bû wekî durra sipî wê seetê

Xewe da der cuyibarê Cennet ${ }^{27}$

\footnotetext{
${ }^{24}$ Sadinî, Mela Huseynê Bateyî Jiyan, Berhem û Helbestên Wî, 190.

${ }^{25}$ Türk Dil Kurumu, “Türk Dil Kurumu Sözlükleri” Pêgehîn: 22yê Adarê 2018. https://sozluk.gov.tr/?kelime

${ }^{26}$ Sadinî, Mela Huseynê Bateŷ̀ Jiyan, Berhem û Helbestên Wî, 175.

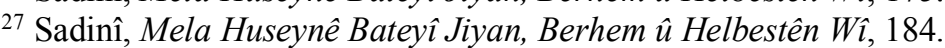


Ew Hebîbê rohnîya heft asîman

Herdu 'alem qalib, ew rûh û rewan ${ }^{28}$

De çi bêjim ne'tê zatê enwerî

Ê ku 'alem cumle bo wî çêkirî́29

Wek ku tê dîtin Bateyî Hz. Mihemed dişibîne durra spî ku ew pir biqîmet e, wî dişibîne ronahiya heft asîmanan, ji bo şexsê wî dibêje ew rûh û rewan e û alem ji bo wî hatiye çêkirin. Dema serî heta dawiyê bê xwendin wê bê dîtin ku pesin û mezinkirineke çawa dewlemend di tevahiya mewlûdê de heye.

Melayê Bateyî di mewlûda xwe de behsa îradeya mutlaq a Xwedê, xuliqandina alemê, wesfên Hz. Mihemed, xususiyetên wî yên ji însanên din cudatir in, meqama pêxembertiyê û mijarên din dike. Di her yek beyteke xwe de peyvên xemilandî û bimene bi kar tîne. M. Zahir Ertekîn van pesn û mijaran wiha dabeş dike;

"1- Pesnên Heqîqueta Mûhemmedî. Pesnên wek 'Ronahîya heft asîman, Xeyrul Beşer' Sultanê Cîhan' dikevin bin vê beşe.

2- Pesnên hezkirina Xwedê. Di ve bêşê de hezkirina Xwedê li hember Resûlê Xwedê (s.x.l), wek 'Canê baqî, Xasê mehbûbê Celîl' tê dîtin.

3- Pesnên girêdayê bi jîyana wî ya dinyewî û sinc û xawênên însanî. Di vê beşe de yetimbûnîya wî, wefaya wî, 'izzeta wî, camêrtîya wî destnîşan bûye.

4- Pesnên derbarê pexembertîya wî. Pesn û medhên girêdayî bi pêxembertîya wî di vê beşê de tê ditîn. Bi taybet xesletên derbarê mezinahîya pêxemberiya wî, wek; 'Xatemê pêxemberan, Xitmirrersûl, Ehmedê 'Alî 'elem, îftîxarê enbîya' û wd.

5- Pesnên derbarê xesletên Wî yên derheqê ummetê de. Di vê beşê de bi xûy, xeslet û taybetîyên ku ummet ji Cenabê Pêxember sûd werdigire hatîye nivîsandin. Wek; 'Şe'fî'ulmuznibîn, darûyê her 'illetê, Destegîr û mustexasê herdû kewn"30

Wek ku Ertekîn jî dabeş kiriye Melayê Bateyî di gelempêriya mewlûdê de behsa van mijaran dike, lê dema pesnê Xwedê û Hz. Pêxember dide ayet, hedîs, hunerên edebî, qafiye, teswîr, sembol û gelek tiştên bi vî rengî bi kar tîne ku ev tişt der barê uslûba wî de agahiyê didin. Bateyî bi metodeke dîdaktîk (tişta ku agahî dide, hîn dike) ve mewlûda xwe nivîsandiye. Ji ber vê ye ku kurd di medreseyan de dixwînin û wê fêrî zarokan dikin. Ji ber vê uslûba dîdaktîk, bi qafiye û rewan e ku ew zû tê jiberkirin û xwendin.

\footnotetext{
${ }^{28}$ Sadinî, Mela Huseynê Bateyî Jiyan, Berhem û Helbestên Wî, 177.

${ }^{29}$ Sadinî, Mela Huseynê Bateyî Jiyan, Berhem û Helbestên Wî, 209.

30 M. Zahir Ertekin, "Pesn û Wesfên Hz. Pêxember (s.x.1.) Di Mewlûda Melayê Bateyî De", 1. Uluslararası Zap Havzası Uleması Sempozyumu Bildirileri (Hakkari, 26-29 Nisan 2018) ed. Yaşar Kaplan-Murat Adıyaman-Emin Yıldırım (İstanbul: Hakkari Üniversitesi Yayınları, 2018), 754.
} 


\subsubsection{Bikaranîna Ayet, Hedîs û Rîwayetan}

Alim û nivîskarên misilman dema berhemek nivîsandine pişta xwe dane çavkanî û referansên dînî. Ji Qur'anê ayetan, ji pêxember hedîsan, ji çîrokên dînî û tesewufî̀ jî meseleyan hilbijartine û ew di berhemên xwe de bi kar anîne. Ev kevneşopî di nav edebiyata klasîk a kurdî de jî reng vedaye ku mirov dikare şopên wê di mewlûda Bateyî de jî bibîne. Melayê Bateyî di mewlûda xwe de hin caran ayet, hin caran hedîs û hin caran jî bûyer û rîwayetên dînî bi kar anîne ku pesnê pêxember bide. Ev jî di mewlûda wî de şêwazek e. Mînak di Qur' ana Pîroz sureya Duhayê de dibêje "Tu êtîmekî bûyî ma wî tu dîtî û nesitirandî?" 31 Ev ayet ji bo Bateyî dibe nexşerê û ew behsa êtîmbûna Hz. Pêxember dike. Jinên şîr didin dergûşan naxwazin derguşeke êtîm bimêjînin, lê Helîmeya Sadiyan wî qebûl dike û dimêjîne. Bateyî wiha behsa vê mijarê dike;

Gotê:"Her bîne ewî tiflê yetîm"

"Qet tewekkelna "elellahîl-kerîm"

Dê çi key tu ba yetîmê bê peder"

Ma Helîme damena sebrê duker

Hate çûnê kariwanî kir cihêz

Dîti Haris rohnikê wê bûne rêz

Gotê Haris: "Ez dibînim tu xudûk"

Gotê: "Heqq e! Dê biçim ez bê buçûk"32

Dîsa ayeteke din a ku dibêje "Saet (qiyamet) nêzîk bû, hîv bû du qetan. Ew dema mucîzeyekê dibînin rûyê xwe vedugerînin û dibêjin ev sêreke daîmî ye."33 Ji bilî vê hin rîwayet jî dibêjin di dema Hz. Pêxember de hîv bûye du qetan û mirovan ev bûyer dîtine. Melayê Bateyî di paşgotina mewlûdê de bal dikşîne mijara perçebûna hîvê û bi van referansan pesnê pêxember dide. Dibêje yek nêrîneke wî ve hîv bû du perçeyan. ${ }^{34}$

"Ehmeda çavê te ma zaxel beser

Yek işareta te inşeqqel qemer" 35

\subsubsection{Hunerên Edebî yên Mewlûdê}

Mela Huseynê Bateyê wek nivîskarên din ên serdema klasîk di vê mewlûda xwe de ji hunerên edebî sûd wergirtiye ku berhema wî bêtir xurt û dewlemend bibe. Di mewlûdê de hin cureyên vegotinê û hunerên edebî hatine bikaranîn, me behsa hinekan kir. Lê dibe ku ew ji yên me tespîtkirin zêdetir bin.

\footnotetext{
${ }^{31}$ Duha $93 / 6$

32 Sadinî, Mela Huseynê Bateyî Jiyan, Berhem î Helbestên Wî, 215.

33 Qamer 54/ 1-2.

${ }^{34}$ Nurullah Agitoğlu, "Molla Hüseyin Bâtevî’nin Şiirlerindeki Hadisler Üzerine Bazı Değerlendirmeler", Uluslararası Beytuşşebap Ve Molla Hüseyin Bateyî Sempozyumu (Şırnak, 20-21 Eylül 2014), ed. İbrahim Baz (İstanbul: Şırnak Üniversitesi Yayınları, 2015), 126.

${ }^{35}$ Sadinî, Mela Huseynê Bateyî Jiyan, Berhem û Helbestên Wî, 232.
} 
3.3.2.1. Teşbîh: Ev peyva erebî ya ku di edebiyatê de wek rêbazeke hunerê tê bikaranîn tiştekî şibandina tiştekî dinê ye. ${ }^{36}$ Melayê Bateyî di mewlûdê de gelek hunerên edebî ji bo pesn û wesfên Hz. Pexember bi kar anîye ku teşbîh jî ji wan yek e. Bi vê rêbazê ve mene xurt dibe û tahmeke edebî derdikeve holê. Bateyî hin caran Hz. Mihemed şibandiye ronahiya heft asîmanan, can û ruhê herdu aleman, hin caran jî ew şibandiye durra spî û wî wek dermanê hemû derdan terîf kiriye;

Ew Hebîbê rohnîya heft asîman

Herdu 'alem qalib, ew rûh û rewan ${ }^{37}$

3.3.2.2. Îştîqaq: Ev peyva ku koka wî erebî ye tê meneya piraştin, jê zêdebûn, ji kokekê çêbûnê. Wek têgeheke edebî peyvên ku ji heman reh û bingehê tên di hevok an jî beytekî de li cem hevdu bikaranîn e. Ji bo ku mene û deng xurt bibe, vegotineke biaheng derkeve holê tê bikaranîn. ${ }^{38}$

Karîsazê bende û sultanê can

$\underline{\text { Rehîm û Rehman Latîf û Mihriban }}{ }^{39}$

Peyvên "rehîm" û "rehman" ên di vê beytê de derbas dibin ji tîpên erebî "r, h, m"yê tên. Yanê ev herdu peyv ji heman rehê çêbûne ku ji bo hunera îştiqaqê mînakeke baş e.

3.3.2.3. Îstîfham: Peyva îstîfhamê peyveke erebî ye û koka wî ji tîpên "f, h, m”yê tê. Meneya wê pirs e. Ji hêla edebî ve ev hunerek e, ji bo ku balê li ser gotinekê û tiştekî bikşîne, fikr û ramanan fêm bike pirs pirskirin e. Gelemperî pirsên wek "kîjan, çi, kî, çima" tên pirsîn. ${ }^{40}$ Mela Huseynê Bateyî di vê beyta mewlûdê de dibêje;

De çi bêjim ne’tê zatê enwerî

Ê ku 'alem cumle bo wî çêkirîn ${ }^{41}$

Li vir pirsa "çi" ji bo hunera îstifhamê mînak dikare bê nîşandan. Lewra li vir her çiqas bibêje "ez çi bibêjim" û vê pirsê bike jî, di eslê xwe de dizane wê çi bibêje, bersivê di hundirê xwe de dide. Wek mene dixwaze bibêje her tişt dikare bê gotin, bi hezaran tiştên xweş û baş ji bo wî bên gotin jî hindik e.

3.3.2.4. Tezad: Peyva tezadê peyveke erebî ye. Meneya wê dijbûn e, dijberî û nakokî ye. Ji hêla edebîyatê ve peyvên ku dijî hev in di vegotinê de bi hev re bikaranîn e. ${ }^{42}$

Dohtê çakanê Qureyş û hem 'ereb

Muntezîr bûn pêkve bo wî roz û ș $\underline{s e b}^{43}$

\footnotetext{
${ }^{36}$ Ethem Cebecioğlu, Tasavvuf Terimleri ve Deyimleri Sözlüğü, (Ankara: Ağaç Kitapevi Yayınları, 2009), 272.

37 Sadinî, Mela Huseynê Bateyî Jiyan, Berhem û Helbestên Wî, 177.

38 Bahir Selçuk, "Divan Şiirindeki Ses Ve Ahenkle İlgili Sanatlara Genel Bir Bakış", Adıyaman Üniversitesi Ulusal Eski Türk Edebiyatı Sempozyumu, (Adıyaman, 15-16 Mayls 2009), ed. Süleyman Çaldak- İbrahim Halil Tuğluk (Ankara: Adıyaman Üniversitesi Yayınları, 2010), 486.

${ }^{39}$ Sadinî, Mela Huseynê Bateŷ̀ Jiyan, Berhem û Helbestên Wî, 175.

${ }^{40}$ Kadri Yıldırım, Ehmedê Xanî Mem $\hat{u}$ Zîn Çeviri ve Kavramsal Tahlili, Çapa Duyemîn (Stenbol: Weşanên Avesta, 2013), 55.

${ }^{41}$ Sadinî, Mela Huseynê Bateŷ̂ Jiyan, Berhem û Helbestên Wî, 209.

42 Türk Dil Kurumu, "Türk Dil Kurumu Sözlükleri”.

${ }^{43}$ Sadinî, Mela Huseynê Bateŷ̀ Jiyan, Berhem û Helbestên Wî, 190.
} 
Wek ku tê zanîn roj û şev du tiştên dijberî hevdu ne, yek ronahî ye û ya din jî tarî ye û du wextên cuda ên rojekê ne. Helbet meneyên wan ên mecazî jî hene. Bateyî di vê beytê de peyvên "roz" û "şeb" bi kar anîye û hunera tezadê derxistiye pêş.

3.3.2.5. Telmîh: Telmîh bi meneya xwe ya ferhengê "çirseçirsk biriqandin" e. Lê wek têgeh di îfadeyê de bi rêya temsîlê îşaretê bûyer, çîrok, ayet, hedîs baweriyên cuda û h.w.d kirin e. ${ }^{44}$ Yanê tişta ku dixwaze bê gotin şûna rasterast gotinê bi awayekî sergirtî û bi îma, temsîl û işaretan yanê tiştên din ve vegotin e. Bateyî di mewlûda xwe de bi awayekî serkeftî nîşan dide ku haya wî ji ilmê îslamî heye û vê ilmê xwe di nav beytên xwe de cih dike. Mînak dema di vê beyta jêrê de behsa hin navan dike "Hewwa", "Sara", "Asîye" û "Meryem" em dizanin ku ew ne jinên li rêzê ne û ji Amîneya Hz. Pêxember re bûne alîkar ku ew biwelide. Ev navên ku Bateyî behsa wan dike di hemû dînên semawî de jinên navdar in, ji ber vê Bateyî bi van navan ve wan jinan refere dike.

Ew kî bûn? Hewwa û Sara Asîye

Ya li pêşim Meryema 'Îmranî ye ${ }^{45}$

3.3.2.6. Tekrîr: Tekrîr peyveke erebî ye û meneya wê dubarekirin, car din gotin e. Di nivîsek an jî helbestekê de ji bo mene û têgeh xurttir bibe li dû hevdu dubarekirinê re tê gotin $\mathrm{ku}$ ev hunereke vegotinê ye. ${ }^{46}$ Mela Huseynê Bateyî di beşa mewlûdê ya bi serenava "Bûna Pêxember" de vê hunera vegotinê gelek caran bi kar anî ye. Peyva "merheba" di van beytan de tekrîr in;

Merheba ey şemsê taban merheba

Merheba ey canê canan $\underline{\text { merheba }}^{47}$

\subsubsection{Qafiye}

Bi erebî "qafiye", bi frensizî "rime" bi îngilizî jî "rhyme" di helbest û stranan de yek ji hêmana ahengê ye ku hêza wê berhemê xurt dike. Bi saya qafiyeyê ew helbest tesîrê zêdetir li ser gotinê dike. Qafiye di dawiya risteyên helbestan de tîpên ku heman dengî didin û tên dubarekirin in. ${ }^{48}$ Heke berfireh bê terîfkirin mirov dikare bibêje qafiye; di serî, navîn an jî dawiya risteyan de tîp, peyv an jî dengên ku tên dubarekirin, wek hevdu tên nivîsandin lê meneyên cuda didin re tê gotin.

Nîvqafîye, qafiyeya tam, qafîyeya dewlemend û qafîyeya tunç cureyên qafîyeyê ne. Mela Huseynê Bateyî hema ji serî bigre heta dawiyê mewlûda xwe bi qafiyeyê nivîsandiye, hemû cureyên qafîyeyê bi kar anîye. Şêwaza vegotina wî û qafiyeyên di mewlûdê de derbas dibin dewlemendiya uslûba wî nîşan dide.

\subsubsection{Nîvqafîye}

Di dawiya risteyan de heke dengek bişibe hevdu jê ra dibêjin nîvqafiye. Melayê Bateyî di mewlûdê de gelek caran nîvqafiye bi kar aniye. Ji bo nîvqafiyeyê ev beyt dikare mînak bê nîşandan. Tîpa "f”" yê ya di peyvên dawiya risteyan de dişibin hevdu nîvqafiye ne;

\footnotetext{
${ }^{44}$ Ahmet Kartal, "Türk Edebiyatında Belâgat Çalışmaları Ve "Tezâd" ve "Telmîh" Sanatlarına Eleştirel Bir Bakış, Ç. Ü. Sosyal Bilimler Enstitüsü Dergisi, 16/1, (Haziran 2007): 418.

${ }^{45}$ Sadinî, Mela Huseynê Bateŷ̀ Jiyan, Berhem û Helbestên Wî, 204.

46 Türk Dil Kurumu, "Türk Dil Kurumu Sözlükleri”.

${ }^{47}$ Sadinî, Mela Huseynê Bateŷ̀ Jiyan, Berhem û Helbestên Wî, 205.

${ }^{48}$ Erman Altun, Türk Halk Edebiyatına Giriş, (İstanbul: Kitabevi Yayınları, 2004), 85.
} 
Sed hezar û hem çihar û bîst elf

Her yekî bûyek Nebiyê dil șikerf"49

\subsubsection{Tamqafiye}

Di vê cure qafiyeyê de du tîp (yek jê dengar û ya din jî dengdêr) dişibin hevdu û di nav xwe de ahengekê çêdikin. Bateyî di mewlûdê de gelek caran bi kar aniye, mînak di van risteyan de tîpên "e" û "t $t$ " di nav hev de biqafiye ne.

Go wî pêxemberê 'alî sifet

Mewlûda min herkesê mazin $\underline{\text { biket }}^{50}$

\subsubsection{Qafiyeya Dewlemend}

Sê an jî zêdetir deng dema dişibin hevdu û bi heman şiklî tên nivîsandin ev wek qafiyeya dewlemend tê binavkirin. Di mewlûda Mela Huseynê Bateyî da ji bo vê cureyê mînak gelek in, em dikarin vê beytêmînak nîşan bidin;

Hat-i Cîbrîl û melaîk Fewcî fewc

Çar kenarê Mekehê bûn mewcî mewc ${ }^{51}$

Peyvên "fewc" û "mewc" di nav hevdu de bi qafîye ne. Tîpên "e, w, c" wek ku tê dîtin di dawiya herdu peyvan de dişibin hevdu. Ji ber ku sê tîp dişibin hevdû ew qafîyeya dewlemend e.

\subsubsection{Qafiyeya Tunç}

Peyveke di dawiya risteyê de derbas dibe heke di nav peyveke dawiya risteyeke din de jî derbas bibe ev deng dişibin hevdu ku jê ra dibêjin qafiyeya tunç. Ev wek cureyeke qafiyeya dewlemend tê qebûlkirin. Ev beytên Bateyî ji bo vê mînak in;

Destegîr û mustexasê herdu kewn

Bo gunehkaran penah û pişt $\hat{u}$ 'ewn $^{52}$

Di dawiya van beytan de peyvên "kewn" û "ewn" qafîyeyê derdixin holê. Di risteya ewil de peyva "kewn" hatiye bi kar anîn, di risteya duyem de jî tîpa "k" yê ketiye peyveke nû ya ku gelekî nêzîkî wê "ewn" hatiye nivîsandin.

\subsubsection{Asonans (Ahenga Dengdêran)}

Heke di berhemên edebî de ji heman dengdêran (a, ê, î, o, û, e, i, u) yek an jî çend heb her tim li dû hev bên dubarekirin, ji ber vê dubarekirinê di vegotinê de ahengek çêbibe û melodiyek derdikeve holê ku ev wek asonans (ahenga dengdaran) tê binavkirin.

Merheba ey geșteyê behra heqîq

Merheba ey dîdeyê ehlê terîq ${ }^{53}$

\footnotetext{
${ }^{49}$ Sadinî, Mela Huseynê Bateyî Jiyan, Berhem û Helbestên Wî, 182.

${ }^{50}$ Sadinî, Mela Huseynê Bateyî Jiyan, Berhem û Helbestên Wî, 179.

${ }^{51}$ Sadinî, Mela Huseynê Bateyî Jiyan, Berhem û Helbestên Wî, 204.

${ }^{52}$ Sadinî, Mela Huseynê Bateyî Jiyan, Berhem û Helbestên Wî̀, 177.

${ }^{53}$ Sadinî, Mela Huseynê Bateyî Jiyan, Berhem û Helbestên Wî, 206.
} 
Di vê beyta Bateyî de tîpa "e"yê 13 caran hatiye dubarekirin ku dema beyt tê xwendin ahengek derdikeve holê, balê dikşîne li ser xwe û gotin xurttir dibe.

\subsubsection{Alîterasyon (Ahenga Dengdaran)}

Alîterasyon ji bo hevahengiyê dubarekirina heman dengan e. ${ }^{54}$ Di helbestan de dema heman dengdar tê dubarekirin ahengek derdikeve holê ku ji vê re dibêjin alîterasyon. Hin caran di serê peyvan de, hin caran di nav peyvan de û hin caran jî di dawiya peyvan de tê bikaranîn. Dubarekirina tîpan û dengan dibe sedema melodiyekê û gotin xweştir dibe.

Dê çikem ya Reb meded mîrê mezin

Wa Muhammed rohniya çavê di $\mathbf{m i n}^{55}$

Melayê Bateyî di vê beytê de dema behsa Hz. Mihemed dike tîpa "m" yê 7 caran dubare dike ku ev tîpa dengdar jî ji bo alîterasyonê dikare bibe mînak.

\subsubsection{Nîda}

Nîda hunerek vegotinê ye ku di edebiyatê de gelek caran derdikeve pêşberî xwîneran. Nîda ji bo gazîkirin û bangkirina kesekî an jî tiştekî tê bikaranîn. Hest û kelecana xurt bi saya nîdayê tê vegotin û gelemperî baneşanên hêy, ey, ax, wax, eywax, lo, lê nîşaneyên nîdayê ne. Di vê hunerê de li hember muxatabek, kesek heye ku ew tê hezkirin an jî gilî û gazîn jê tê kirin. Nîda di edebiyata klasîk de ji bo ahengê hêmaneke girîng e ku Melayê Bateyê jî di mewlûdê de bi kar anîye;

Ey şivanê kûdeka zîba delêr

Xwezya wî berxê ji dîdara te têr ${ }^{56}$

Di vê mînaka li jor hatiye dayîn de baneşîna "Ey", di vê mînaka duyem a ku li jêrê hatiye dayîn de jî baneşîna "Ya" nîda ne. Herdu jî li hember muxatabê xwe kelecanê nîşan didin û gotinê xurt dikin.

Ya Resûlellah! Resûlê îns û cin

Ya şefî‘ ê sedrê dîwana/eywana mezin ${ }^{57}$

\subsubsection{Cotpeyv}

Di peysaziyê de heke du peyvên ji hêla mene an jî deng ve dişibin hev, du peyvên wek hevdu yan jî du peyvên li dijî hevdu dema li dû hev bên rêzkirin peyveke nû ya ku meneya wê cuda derdikeve holê û ji vê re dibêjin cotpeyv. Hin caran du navdêr, hin caran du rengdêr, hin caran du hoker û hin caran jî du lêker dibin cotpeyv û peyveke nû derdixin holê. Gelemperî du peyv ji bo cotpeyvê tên bikaranîn. Hin caran ji du peyvan zêdetir peyv jî dikarin bibin cotpeyv. Armanca cotpeyvan ewe ku hêza vegotinê xurt û dewlemend bibe, di vegotinê de ahengek derkeve holê. Di mewlûdê de ji bo cotpeyvan gelek mînak hene ku ji van hinek ev peyv in; xal û xet, têr û tijî, pak û temîz, behr û ber, dexl û dan, bejn û bal, ezman û dev, roj û şev. Mînak;

\footnotetext{
54 M. Zahir Ertekin, Mewlûda Mele Eliyê Baqûstanî Metn $\hat{u}$ Lêkolîn, Çapa Yekem (Hewlêr: Destnivîsxaneya Zanîngeha Soran, 2017), 39.

${ }^{55}$ Sadinî, Mela Huseynê Bateyî Jiyan, Berhem û̀ Helbestên Wî, 219.

${ }^{56}$ Sadinî, Mela Huseynê Bateyî Jiyan, Berhem û Helbestên Wî, 222.

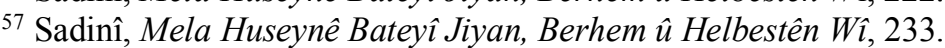


Ey hetîm û ey herem pak û temîz

Bo te hate bejin û balayê 'ezîz ${ }^{58}$

Asîmanê bêstûn, wî kir bedîd

Suretê ba xal û xet wî aferîd ${ }^{59}$

\section{ENCAM}

Mela Huseynê Bateyî ji ber ku cara ewil bi zimanê kurdî mewlûdek nivîsandiye, di edebiyata klasîk a kurdî de xwedî cihekî taybet e. Ev mevlûd bûye sedem ku kurd êdî bi zimanê xwe mewlûdê bixwînin. Piştî mewlûda wî nivîsîna mewlûdên kurdî jî dest pê kiriye. Yên ku mewlûda Melayê Bateyî ji xwe re wek çavkanî hilbijartine gelemperî xweser tevnegeriyane, ketine bin tesîra uslûb û vegotina wî. Ji ber vê ye kesên din di nav kurdan de qasî wî bi nav û deng nebûne. Di medreseyên kurdan de piştî hînkirina Qur'anê perwerdeya mewlûda kurdî jî hatiye dayîn û ev kevneşopî hê jî dewam dike.

Mewlûd bi uslûbeke dîdaktîk hatiye nivîsandin, ji ber vê ye ku zêdetir hatiye xwendin û jiberkirin. Bateyî di mewlûdê de hunerên edebî yên wek îştiqaq, tekrîr, îstifham, nîda, tezad, asonans û h.w.d bi kar aniye ku pesnê pêxember bi vî awayî xurttir û geştir bide. Bikaranîna van hunerên edebî û cureyên qafîyeyê ya di mewlûdê de helbestvaniya wî nîşan dide. Dema mewlûd serî heta dawiyê bê xwendin wê bê dîtin ku uslûbeke têrhuner û dewlemend heye. Herî dawîn mirov dikare bibêje Melayê Bateyî bi mewlûda xwe ya ku him ji hêla ziman, huner û vegotina edebî û him jî ji hêla uslûb û şêwaza xwe ya xweser ve di dîroka edebiyata klasîk de navê xwe daye nivîsandin. Mohra wî ya taybet li ser edebiyata kurdî bi zelalî xuya dike û navê wî her tim wê bê bibîranîn.

\section{ÇAVKANî}

Adak, Abdurrahman. Destpêka Edebiyata Kurdî Ya Klasîk. Çapa Sêyem. Stenbol: Weşanên Nûbihar, 2015.

Adak, Abdurrahman. "Destnivîsên Mewlûda Melayê Bateyî Di Arşîva A. Jaba De: Nasandin û Analîz". The Journal Of Mesopotamian Studies 2/2, (Havîn: 2017): 1-29.

Agitoğlu, Nurullah. "Molla Hüseyin Bâteyî’nin Şiirlerindeki Hadisler Üzerine Bazı Değerlendirmeler". Uluslararası Beytuşşebap Ve Molla Hüseyin Bateŷ̂ Sempozyumu Bildirileri (Şırnak, 20-21 Eylül 2014). Ed. İbrahim Baz. 119-128. İstanbul: Şırnak Üniversitesi Yayınlar1, 2015.

Altun, Erman. Türk Halk Edebiyatına Giriş. Stenbol: Kitapevi, 2004.

Cebecioğlu, Ethem. Tasavvuf Terimleri ve Deyimleri Sözlüğü. Ankara: Ağaç Kitapevi Yayınları, 2009.

Doğru, Rabia. "Kara Vâîz ve Mevlid'i”.Ondokuz Mayıs Üniversitesi İlahiyat Fakültesi Dergisi 0/39 (2015): 221-250.

\footnotetext{
${ }^{58}$ Sadinî, Mela Huseynê Bateyî Jiyan, Berhem û Helbestên Wî, 227.

${ }^{59}$ Sadinî, Mela Huseynê Bateŷ̀ Jiyan, Berhem û Helbestên Wî, 175.
} 
Ekinci, Ramazan. "Behiştî Mahlaslı Şairlere Ait Mevlitler, Behiştî Ahmed Sinan'ın Mevlid-i Şerîfi”. Sufi Araştırmaları Dergisi 5/10 (Yaz 2014): 17-79.

Eroğlu, Süleyman. "Edebî Bir Tür Olarak Mevlitler-Şekil Özelliklerine Göre Bazı Değerlendirmeler", U.Ü. Fen Edebiyat Fakültesi Dergisi 11/18 (2010): 126-127.

Ertekin, M. Zahir-Nurettin Ertekin. "Kurtedîroka Mewlûdnameyên Kurd̂̂". Şarkiyat ICSS'17 Uluslararast Sosyal Bilimler Kongresi/International Congress of Social Science (Diyarbakır, 14-17 Eylül 2017). Ed. Mehmet Bilen. 149- 155. Diyarbakır: Şarkiyat Vakfi, 2017.

Ertekin, M. Zahir. Mewlûda Mele Eliyê Baqûstanî Metn î Lêkolîn. Çapa Yekem. Hewlêr: Destnivîsxaneya Zanîngeha Soran, 2017.

Ertekin, M. Zahir. "Pesn û Wesfên Hz. Pêxember (s.x.1.) Di Mewlûda Melayê Bateyî De”. 1. Uluslararası Zap Havzası Uleması Sempozyumu Bildirileri (Hakkari, 26-29 Nisan 2018). Ed.Yaşar Kaplan-Murat Adıyaman-Emin Yıldırım. 753-770. İstanbul: Hakkari Üniversitesi Yayınları, 2018.

Îlhan, Zîver. Mewlûda Mela Huseynê Bateyî Metnê Rexneŷ̂ û Lêkolîn. Çapa Yekem. Stenbol: Weşanxaneya Avesta, 2016.

Karacan, Hasan-Aykut, Nurettin. “Mele Hüseynê Bateyî’nin Mewlid-i Nebî Adlı Eseri İle Mele Süleyman Kurşun'un Mewlida Pêxember Adlı Eserinin Karşılaştırılması". Bingöl Üniversitesi Yaşayan Diller Enstitüsü Dergisi 1/2 (Kasım 2015): 123-141

Kartal, Ahmet. "Türk Edebiyatında Belâgat Çalışmaları Ve "Tezâd" ve "Telmîh" Sanatlarına Eleştirel Bir Bakış”. Ç.Ü. Sosyal Bilimler Enstitüsü Dergisi 16/1 (Haziran 2007): 413-428.

Sadinî, M. Xalid. Mela Huseynê Bateŷ̂ Jiyan, Berhem ûu Helbestên Wî. Çapa Yekem. Stenbol: Weşanên Nûbihar, 2010.

Sadinî, M. Xalid. "Mela Huseyînê Bateyî, Jîyan û Berhemên Wî", Uluslararası Beytuşşebap Ve Molla Hüseyin Bateyî Sempozyumu Bildirileri (Şırnak, 20-21 Eylül 2014), Ed. İbrahim Baz. 83-102 İstanbul: Şırnak Üniversitesi Yayınları, 2015.

Selçuk, Bahir. "Divan Şiirindeki Ses Ve Ahenkle İlgili Sanatlara Genel Bir Bakış", Adlyaman Üniversitesi Ulusal Eski Türk Edebiyatı Sempozyumu (Adlyaman, 15-16 Mayls 2009). Ed. Süleyman Çaldak- İbrahim Halil Tuğluk. 483- 491. Ankara: Adıyaman Üniversitesi Yayınları, 2010.

Qanatê, Kurdo. Tarîxa Edebiyata Kurdî. Çapa Yekemîn. Diyarbekir: Weşanên Lîs, 2010 .

Yıldırım, Kadri. Ehmedê Xanî Mem û Zîn Çeviri ve Kavramsal Tahlili. Çapa Duyem. Stenbol: Weşanên Avesta, 2013.

Türk Dil Kurumu. “Türk Dil Kurumu Sözlükleri”. Pêgehîn: 22yê Adarê 2018. https://sozluk.gov.tr/?kelime 